\title{
Lihasikojen hännänpurennan esiintyvyys Suomessa ja yhteydet teurashylkäyksiin
}

\author{
Anna Valros, Tanja Häkkinen, Hanna Rintala, Susanna Ahlström ja Hannu Saloniemi
}

Eläinten hyvinvoinnin tutkimuskeskus, Eläinlääketieteellinen tiedekunta, Helsingin yliopisto, PL 57, 00014 Helsingin yliopisto, anna.valros@helsinki.fi

\begin{abstract}
Johdanto
Hännänpurenta on sian käyttäytymishäiriö, joka johtaa vakaviin hyvinvointiongelmiin. Lisäksi hännänpurenta on aina osoitus siitä, että sikojen hyvinvointitaso ei ole toivotulla tasolla. Sekä krooninen että akuutti stressi voivat laukaista hännänpurentaepidemian. Hännänpurennan esiintyvyyttä voidaan siten yhdistää tiettyihin kasvatusoloihin, kuten virikkeettömyyteen ja ahtauteen (Moinard ym., 2003) mutta sitä voi myös esiintyä hyvässä sikalassa, esimerkiksi jos lämpötila on liian korkea tai alhainen tai ruokinta puutteellinen jonkun ravintoaineen osalta (Schröder-Pedersen \& Simonsen, 2001). Hännänpurenta aiheuttaa lisääntynyttä sairastavuusriskiä, muun muassa tulehduksiin paiseiden muodossa (Huey, 1996), alhaisempaa päiväkasvua ja kärsimystä purrulle sialle (Wallgren \& Lindahl, 1996). Tämän tutkimuksen tarkoituksena oli tutkia hännänpurennan esiintyvyyttä suomalaisilla lihasioilla ja selvittää hännänpurennan yhteydet tavallisimpiin teurashylkäyssyihin.
\end{abstract}

\begin{abstract}
Aineisto ja menetelmät
Viikon aikana kerättiin yhdellä suomalaisella teurastamolla tiedot 10852 siasta. Havainnot tehtiin teuraslinjalla kalttauksen jälkeen. Jokaisen sian hännän kunto rekisteröitiin kahdella asteikolla: pituuden ja vaurion laadun mukaan. Hännät määriteltiin silmämääräisesti joko pitkiksi $(>10 \mathrm{~cm})$ tai lyhyiksi $(<10 \mathrm{~cm})$. Lisäksi häntä määriteltiin joko kokonaan terveeksi tai varioiduksi. Jälkimmäinen luokka (vaurioituneet) jaettiin parantuneisiin ja tuoreisiin vaurioihin. Häntä, joka oli sekä lyhyt että tuoreesti varioitu määriteltiin jälkikäteen vakavan hännänpurennan tapaukseksi. Tämän lisäksi rekisteröitiin kaikkien sikojen sukupuoli. Hylkäystiedot saatiin eläinkohtaisesti tarkastuspöytäkirjojen kautta. Tarkastuksen suoritti normaalin rutiinin mukaisesti teurastamon tarkastuseläinläkäri.

Tutkimuksessa selvitettiin hännänpurennan vaikutusta kokonaishylkäyksien määrään (kaikki syyt yhteensä) sekä määrään hylkäyksiä niveltulehdusten, märkäpesäkkeiden ja luunmurtumien takia. Lisäksi selvitettiin häntävaurioiden vaikutusta hylättyjen ruhonosien osuuteen. Yhteydet häntävaurioiden ja sukupuolen sekä häntävaurioiden ja teuraslöydösten sekä hylättyjen osien välillä analysoitiin käyttämällä $\chi^{2}$ - testiä (SPSS 8.0 for Windows). Eri häntävaurioluokkien vaikutus hylkäyssyiden esiintymiseen ja hylättyjen ruhonosien osuuteen verrattiin aina tervehäntäisten sikojen vastaaviin lukuihin. Riskisuhde (RR) on suhteellinen luku, joka kuvaa tietyn altistajan (esim. häntävaurion) vaikutusta tutkittavan ilmiön (esim. ruhonhylkäys) esiintyvyyteen. Jos riskisuhde on $>1$ lisää altistaja ilmiön esiintyvyyttä, jos riskisuhde on $<1$, vähentää altistaja ilmiön esiintyvyyttä.
\end{abstract}

\section{Tulokset ja tulosten tarkastelu Hännänpurennan esiintyvyys}

Yhteensä 35 prosentilla tässä tutkimuksessa havaituista sioista oli merkkejä jonkinlaisista hännän vaurioista. Noin kaksi kolmannesta näistä olivat parantuneita vaurioita joten noin 12 prosentilla kaikista sioista oli merkkejä tuoreesta hännänpurennasta. Vakavaa hännänpurentaa nähtiin 1,3 prosentilla kaikista sioista (Taulukko 1). Vakavien hännänpurentatapauksien osuus kokonaishäntävaurioista oli 3,7 prosenttia.

Hännänpurennan esiintyvyys oli odotuksiin verrattuna yllättävän yleistä, varsinkin jos huomioidaan kaikki häntävauriot. Toisaalta, kokonaisvauriolukua pitää tulkita varauksella, sillä hännän vaurion syytä ei pystytty tutkimuksessa varmistamaan. Mikäli hännässä havaittiin jotain epänormaalia, kuten epämuodostumaa tai jos häntä oli selkeästi normaalia lyhyempi, mutta siinä ei ollut tuoreita merkkejä purennasta, se luokiteltiin parantuneeksi häntävaurioksi. Tähän luokkaan on siten saattanut joutua iso määrä muusta kuin hännänpurennasta johtuvia vaurioita, kuten typistettyjä, emakon tallaamia tai muulla tavalla vaurioituneita häntiä.

Tuoreiden hännänpurentojen esiintyvyys $(12 \%)$ on verrattavissa muihin tutkimuksiin. Suomessa on tietääksemme tehty aikaisemmin vain yksi varsinaisesti hännänpurentaa kartoittava 
tutkimus: Tiilikaisen (2000) välitysporsaisiin keskittyvässä tutkimuksessa havaittiin kahdeksan prosentin hännänpurenta-esiintyvyys. Heinonen ym (2001) raportoivat, että hännänpurentaa hoidettiin 69 prosentissa terveysluokan sikaloista ja hoidettujen sikojen määrän mediaani oli 3 prosenttia tilaa kohden.

Ulkomaisissa, teurasikäisillä lihasioilla tehdyissä tutkimuksissa on raportoitu vaihtelevia esiintyvyyslukuja hännänpurennalle. Lukujen vertailun tekee vaikeaksi, että niihin vaikuttavat sekä vaihtelevat käytännöt hännäntypistyksen osalta että puremien vaihtelevat rekisteröintitavat. Esimerkiksi Hunter ym. (1999) raportoivat hännänpurentaesiintyvyydeksi kuudella englantilaisella teurastamolla (62 971 eläintä) kolmeksi prosentiksi typistetyillä sioilla ja yhdeksäksi prosentiksi eitypistetyillä sioilla. Vakavia vaurioita oli promillella $(0,1 \%)$ typistetyistä ja puolella prosentilla eitypistetyistä sioista. Myös Pennyn \& Hillin (1974) aikaisemmassa, englannissa kerätyssä aineistossa (11 811 eläintä), oli suuri ero typistettyjen ja ei-typistettyjen eläinten välillä. Ei-typistetyillä eläimillä hännänpurennan esiintyvyys oli $11,4 \%$ eikä sitä esiintynyt juuri ollenkaan typistetyillä. Isossa ruotsalaisessa tutkimuksessa, jossa hännänpurennan esiintyvyys perustui teurastamon lihantarkastuksen tietoihin, havaittiin vuosina 1995-1996 3,4 \% hännänpurentaesiintyvyyttä (364 631 eläintä) (Holmgren \& Lundeheim, 1997). Norjassa vastaava teurastamon antama luku on noin $4 \%$ (Fjetland \& Kjeastad, 2002).

Taulukko 1. Häntävaurioiden esiintyvyys ja sukupuolijakauma

\begin{tabular}{lrrrrr} 
& $\mathrm{N}$ & $\begin{array}{r}\text { Kaikki siat } \\
(\mathrm{n}=10852)\end{array}$ & $\begin{array}{r}\text { Leikot } \\
(\mathrm{n}=5542)\end{array}$ & $\begin{array}{r}\text { Ensikot } \\
(\mathrm{n}=5310)\end{array}$ & $\mathrm{RR}$ \\
\hline Yhteensä & 3751 & $34,6 \%$ & $38,8 \%$ & $30,2 \%$ & $1,3 * * *$ \\
Parantunut & 2476 & $22,8 \%$ & $25,2 \%$ & $20,4 \%$ & $1,2 * * *$ \\
Tuore & 1275 & $11,7 \%$ & $13,6 \%$ & $9,9 \%$ & $1,4 * * *$ \\
Vakava & 138 & $1,3 \%$ & $1,6 \%$ & $1,0 \%$ & $1,6^{* *}$ \\
\hline
\end{tabular}

\section{Sukupuolijakauma}

Häntävaurioita esiintyi merkittävästi enemmän leikoilla kuin imisillä (Taulukko 1). Suurempi hännänpurennan esiintyvyys leikoilla tukee aikaisempia tutkimustuloksia. Hunter ym (1999) raportoivat, että leikoilla oli 40 prosenttia suurempi riski tulla purruksi kuin imisillä ja Penny \& Hill (1974) raportoivat hännänpurennan esiintyvyydeksi leikoilla 15,7 prosenttia ja imisille 7,7 prosenttia.

Syitä tähän sukupuolijakaumaan on etsitty esimerkiksi sukupuolieroista käyttäytymisessä ja puremistaipumuksesta: sukukypsyyden rajalla olevat imisät ovat aktiivisempia ja kiinnostuneempia toisten eläinten takapuolesta, jolloin riski hännänpurentaan myös kasvaa (Simonsen, 1995). Toisaalta Penny ym. (1981) havaitsivat, että yhden sukupuolen ryhmissä karjut purevat imisiä vähemmän, ja puremat ovat myös näiden osalta vakavammat. Schröder-Pedersen \& Simonsen (2001) arvioivat, että tämä saattaa johtua karjujen korkeammasta aggressiivisuustasosta ja siitä johtuvasta turhautumisesta.

Vielä ei kuitenkaan ole varmaa tietoa siitä, onko hännänpurentakäyttäytymisessä sukupuolieroja, ja jos on, mistä nämä johtuvat. Ei myöskään ole itsestään selvää, että sukupuolijakauma purentakäyttäytymisessä olisi syynä havaittuihin eroihin purennan uhrien sukupuolijakaumassa. Saattaa olla, että sukupuolierot vaikuttavat sen sijaan suoraan siihen, miten helposti siasta tulee hännänpurennan uhri.

\section{Yhteydet teurashylkäyksiin}

Tämän tutkimuksen mukaan kaikenlaiset häntävauriot lisäävät riskiä teurashylkäyksille, myös lievät ja parantuneet tapaukset: Erityisesti vakava hännänpurenta lisäsi hylkäysriskiä huomattavasti. Hylkäyssyistä märkäpaiseet ja niveltulehdukset olivat selkeimmin yhteydessä häntävaurioihin. Ei ole yllättävää, etteivät häntävauriot olleet yhteydessä luunmurtumien esiintyvyyteen, sillä nämä syntyvät usein vasta post mortem (Taulukko 2). 
Hännänpurenta aiheuttaa tulehduksia ja paiseita muualla kehossa, eikä lääkitys aina estä tulehduksien leviämistä (Wallgren \& Lindahl, 1996). Reittejä tulehduksien leviämiselle on useita, sillä hännänpurenta saattaa vaurioittaa sekä ihoa, että lihaksia ja selkärankaa. Tulehdus voi levitä hännästä muualle kehoon muun muassa verenkierron kautta, imunesteen kautta ja suoraan selkäydintä pitkin (Schröder-Pedersen \& Simonsen, 2001).

Tavallisimmin hännänpurenta näyttää aiheuttavan paiseita selän alueella (Huey, 1996). Myös meidän tutkimuksessa havaittiin, että yhteys hännänpurennan ja selkähylkäyksien välillä oli erityisen vahva: selkähylkäyksien riski oli 5,6-kertainen tuoreissa hännänpurentatapauksissa ( $\mathrm{p}<0,001)$, ja jopa 21-kertainen vakavissa hännänpurentatapauksissa $(\mathrm{p}<0,001)$. Myös muiden ruhonosien hylkäysriski oli vahvasti yhteydessä häntävaurioihin: vakava hännänpurenta lisäsi kinkkujen hylkäysriskiä 4,3kertaisesti $(\mathrm{p}<0.001)$, lapojen 6,7 -kertaisesti $(\mathrm{p}<0,001)$ ja muun lihan 10 -kertaisesti $(\mathrm{p}<0.001)$. Riski kokoruhohylkäykselle kasvoi 4,8-kertaiseksi vakavan hännänpurennan seurauksena ( $<<0.01)$.

Huey (1996) raportoi (yli 75000 sian aineisto), että teurashylkäyksiin liittyi hännänpurentaa 62 prosentissa tapauksista, joissa sialla oli tulehduksia useassa paikassa kehoa. Omassa aineistossamme 52 prosentilla sioista, joilta hylättiin ainakin yksi osa, oli merkkejä jonkinasteisesta hännänpurennasta. Sioista, joilla oli paiseiden aiheuttamia hylkäyksiä, noin kolmanneksella oli merkkejä häntävaurioista ja noin neljänneksellä oli merkkejä tuoreesta hännänpurennasta.

Myös lievät ja parantuneet häntävauriot lisäsivät tutkimuksemme mukaan riskiä teurashylkäyksille, joten näihinkin tulisi suhtautua vakavasti. Simonsen ym (1991) raportoi yllättävän suurta tulehdusreaktioiden esiintyvyyttä ulkoisesti terveennäköisissä sikojen hännissä. Nämä tutkijat arvioivat syynä olevan puremat ja vauriot, jotka eivät kuitenkaan ole aiheuttaneet ulkoisesti näkyviä vaurioita. Huey (1996) esitti, että selkäpaiseiden muodostuminen saattaa kestää viikkoja, joten teurastuksen yhteydessä tulehduksen alkuperäinen syy, eli häntävaurio voi jo olla parantunut. Myös esimerkiksi huono hygienia hännäntypistyksen yhteydessä saattaa aiheuttaa paikallisia paiseita.

Taulukko 2. Häntävaurioiden yhteys teurashylkäyksiin: osuus sioista, joilta hylättiin vähintään osa ruhosta ja häntävaurioiden vaikutus hylkäysriskiin (verrattuna tervehäntäisiin sikoihin).

\begin{tabular}{|c|c|c|c|c|c|c|c|c|c|c|}
\hline \multirow[t]{2}{*}{ Hylkäyssyy } & \multirow{2}{*}{$\begin{array}{r}\text { Kaikki } \\
\text { siat } \\
\%\end{array}$} & \multirow{2}{*}{$\begin{array}{r}\begin{array}{r}\text { Tervehäntäiset } \\
\text { siat }\end{array} \\
\%\end{array}$} & \multicolumn{2}{|c|}{$\begin{array}{r}\text { Kaikki } \\
\text { häntävauriot }\end{array}$} & \multicolumn{2}{|c|}{$\begin{array}{r}\text { Parantuneet } \\
\text { häntävauriot }\end{array}$} & \multicolumn{2}{|c|}{$\begin{array}{r}\text { Tuoreet } \\
\text { häntävauriot }\end{array}$} & \multicolumn{2}{|c|}{$\begin{array}{l}\text { Vakavat } \\
\text { puremat }\end{array}$} \\
\hline & & & $\%$ & RR & $\%$ & RR & $\%$ & RR & $\%$ & RR \\
\hline $\begin{array}{l}\text { Kaikki } \\
\text { hylkäykset }\end{array}$ & 7,0 & 5,1 & 10,5 & $\begin{array}{r}2,0 \\
* * *\end{array}$ & 8,8 & $\begin{array}{r}1,7 \\
* * *\end{array}$ & 13,8 & $\begin{array}{r}2,7 \\
* * *\end{array}$ & 26,8 & $\begin{array}{r}5,2 \\
* * *\end{array}$ \\
\hline $\begin{array}{l}\text { Nivel- } \\
\text { tulehdukset }\end{array}$ & 2,9 & 2,3 & 4,2 & $\begin{array}{r}1,9 \\
* * *\end{array}$ & 3,5 & $\begin{array}{l}1,5 \\
* *\end{array}$ & 5,7 & $\begin{array}{r}2,5 \\
* * *\end{array}$ & 12,3 & $\begin{array}{r}5,5 \\
* * *\end{array}$ \\
\hline $\begin{array}{l}\text { Märkä- } \\
\text { pesäkkeet }\end{array}$ & 2,2 & 0,9 & 4,7 & $\begin{array}{r}4,9 \\
* * *\end{array}$ & 3,5 & $\begin{array}{r}3,7 \\
* * *\end{array}$ & 6,9 & $\begin{array}{r}7,3 \\
* * *\end{array}$ & 16,7 & $\begin{array}{l}17,6 \\
* * *\end{array}$ \\
\hline $\begin{array}{l}\text { Luun- } \\
\text { murtumat }\end{array}$ & 1,4 & 1,4 & 1,4 & 1,0 & 1,5 & 1,1 & 1,3 & 1,0 & 0 & $\mathrm{~ns}$ \\
\hline
\end{tabular}

\section{Johtopäätökset}

Häntävaurioiden esiintyvyys oli yllättävän suuri ja osoittaa, että hännänpurenta on vakavasti otettava ongelma suomalaisilla sikatiloilla. Koska häntävauriot kaikissa muodoissaan lisää teurashylkäysriskiä, on selvä, että sen lisäksi, että hännänpurenta on hyvinvointiongelma, se aiheuttaa myös merkittäviä taloudellisia tappioita. Vaikka hännäntypistys kirjallisuuden mukaan vähentää hännänpurentariskiä, oli Suomi edelläkävijämaa kieltäessään typistyksen lailla, sillä hännän typistäminen ei poista taustalla olevia hyvinvointiongelmia, ja aiheuttaa lisäksi sialle kipua sekä saattaa lisätä infektioriskiä. Moni asia hännänpurentaan liittyen on vielä epäselvä. Hännänpurennan taustan ymmärtämiseksi ja hyvinvointisekä tuotantovaikutuksien arvioimiseksi tarvitaan lisätutkimuksia aiheesta. 


\section{Kirjallisuus}

Fjetland, O. \& Kjaestad, H.P. 2002. Halebiting hos gris. Norsk Veterinärtidsskrift 114: 249-253.

Heinonen, m., Hämeenoja, P., Saloniemi, H. \& Tuovinen, V. 2001. Diagnoses and treatments in healthclassified fattening herds rearing pigs all in - all out. Acta Vet. Scand. 42: 365-375.

Holmgren, N. \& Lundeheim, N. 1997. Olika produktionsformer för svin - inverkan på sjukdomsfynd vid slakt. Svensk veternärtidning 49: 625-629.

Huey, R.J. 1996. Incidence, location and interrelationships between the sites of abscesses recorded in pigs at a bacon facory in Northern Ireland. Vet. Rec. 138: 511-514.

Hunter, E.J., Jones, T.A., Guise, H.J., Penny, R.H.C. \& Hoste, S. 1999. Tail biting in pigs 1: The prevalence at six UK abattoirs and the relationship of tail biting with docking, sex and other carcass damage. Pig J. 43: 1832.

Moinard, C., Mendl., M., Nicol, C.J., Green, L.E. 2003. A case control study of on-farm risk factors for tail biting in pigs. Appl. Anim. Behav. sci. 81: 333-355.

Penny, R.H.C. \& Hill, F.W.G. 1974. Observations of some conditions in pigs at the abattoir with particular reference to tail biting. Vet. Rec. 94: 174-180.

Penny, R.H.C., Walters, J.R. \& Tredget, S.J. 1981. Tail biting in pigs: A sex frequency between boars and gilts. Vet. Rec. 108: 35.

Schröder-Pedersen, D. L. \& Sinonsen, H.B. 2001. Tail biting in pigs (Review). Vet. J. 162: 196-210.

Simonsen, H.B. 1995. effect of early rearing environment and tail docking on later behaviour and production in fattening pigs. Acta. Agric. Scand. Sect. A, Animal Sci. 45: 139-144.

Simonsen, H.B., Klinken, L. \& Bindseil, E. 1991. Histopathology of intact and docked pigtails. Br. Vet. J. 147: 407-412.

Tiilikainen, M. 2000. Neljä viidestä porsastuottajasta tuottaa virheettömiä porsaita. laatuvirheistä pahin on purtu häntä. Maatilan pellervo 1: 22-24.

Wallgren, P. \& Lindahl, E. 1996. The influence of tail biting on performance of fattening pigs. Acta Vet. Scand. 37: 453-460. 